\title{
Desenvolvimento e avaliação sensorial de goiaba-passa desidratada osmoticamente
}

\author{
Development and sensory evaluation of osmotically dehydrated guava
}

\author{
Deise Souza de Castro ${ }^{1 *}$, Wilton Pereira da Silva², Josivanda Palmeira Gomes ${ }^{1}$, Juarez Everton Farias Aires ${ }^{3}$, \\ Kalina Ligia Cavalcante de Almeida Farias Aires ${ }^{3}$, Aluízio Freire da Silva Junior ${ }^{3}$ \\ 1 Universidade Federal de Campina Grande (UFCG), Departamento de Engenharia Agrícola, Campina Grande/PB - Brasil \\ 2 Universidade Federal de Campina Grande (UFCG), Departamento de Física, Campina Grande/PB - Brasil \\ ${ }^{3}$ Universidade Federal de Campina Grande (UFCG), Departamento de Engenharia de Processos, Campina Grande/PB - Brasil
}

\section{*Corresponding Author}

Deise Souza de Castro, Universidade Federal de Campina Grande (UFCG), Departamento de Engenharia Agrícola, Campus I, Av. Aprígio Veloso, 882, Bloco CM, $1^{\circ}$ andar, Bodocongó, Caixa Postal: 10.078, CEP: 58429-140, Campina Grande/PB - Brasil, e-mail: deise_castro01@hotmail.com

Cite as: Development and sensory evaluation of osmotically dehydrated guava. Braz. J. Food Technol., v. 21, e2016013, 2018.

Received: Jan. 22, 2016; Accepted: Aug. 10, 2017

\section{Resumo}

Apesar de ser um fruto disponível durante todo o ano, nas regiões de cultivo irrigado das diferentes regiões do país, a goiaba apresenta grande desperdício pós-colheita, associado ao rápido amadurecimento, necessitando da aplicação de técnicas de processamento que diminuam o desperdício deste fruto. Objetivou-se, neste trabalho, estudar o processo de transferência de massa durante a desidratação osmótica de fatias de goiaba, além de avaliar os parâmetros sensoriais da goiaba-passa obtida sob diferentes temperaturas de processo e concentrações de sacarose. Fatias de goiaba cv. Paluma $(3,0 \times 2,0 \times 0,9 \mathrm{~cm})$ foram submetidas à desidratação osmótica em xaropes de sacarose a $40{ }^{\circ} \mathrm{Brix}, 50^{\circ}$ Brix e $60^{\circ}$ Brix, combinados com temperaturas de $30^{\circ} \mathrm{C}, 40^{\circ} \mathrm{C}$ e $50^{\circ} \mathrm{C}$, por meio de planejamento fatorial com ponto central. O pré-tratamento osmótico foi complementado com secagem convectiva a $60^{\circ} \mathrm{C}$ e as goiabas-passa foram estudadas quanto ao processo de transferência de massa na desidratação osmótica, seguida de avaliação sensorial. Verificou-se que a máxima transferência de massa ocorreu durante as quatro horas iniciais de desidratação, sendo a concentração de sacarose o efeito com maior influência na diminuição da quantidade de água e no aumento da incorporação de sólidos. A avaliação dos parâmetros sensoriais demonstrou uma maior preferência dos provadores pelas passas obtidas em menor concentração de sacarose, para os atributos aparência, cor, textura e sabor. Não foram observadas diferenças significativas entre as notas atribuídas pelos provadores para o atributo odor. O perfil sensorial aplicado revelou a boa aceitação do pré-tratamento osmótico quando comparado ao fruto sem tratamento osmótico e seco apenas por secagem convectiva.

Palavras-chave: Transferência de massa; Desidratação osmótica; Aceitação sensorial.

\section{Abstract}

Despite being a fruit available throughout the year in the irrigated regions of the different regions of the country, guava shows great post-harvest losses associated with its rapid ripening, requiring the application of processing techniques that reduce the loss of this fruit. The objective of this work was to study the mass transfer process during the osmotic dehydration of guava slices and evaluate the sensory parameters of the dried guava obtained at different osmosis temperatures and sucrose concentrations. Guava cv. Paluma slices $(3.0 \times 2.0 \times 0.9 \mathrm{~cm})$ were subjected to osmotic dehydration in sucrose syrup at $40^{\circ} \mathrm{Brix}, 50^{\circ} \mathrm{Brix}$ and $60^{\circ} \mathrm{Brix}$ combined with temperatures of $30^{\circ} \mathrm{C}, 40^{\circ} \mathrm{C}$ and $50^{\circ} \mathrm{C}$ using a factorial central point design. The osmotic pre-treatment was complemented by convective drying at $60^{\circ} \mathrm{C}$ and the dried guava slices studied with respect to mass transfer during the process of osmotic dehydration followed by a sensory evaluation. It was found that the maximum mass transfer occurred during the initial 4 hours of dehydration and the concentration of sucrose had the greatest influence in reducing the amount of water and increasing the incorporation of solids. The sensory assessment parameters 
demonstrated that the product most preferred by the panellists was that obtained with lower sucrose concentrations for the attributes of appearance, colour, texture and flavour. No significant differences were observed between the scores awarded by the panellists for the attribute of odour. The sensory profile applied showed good acceptance of the osmotic pre-treatment when compared to the in natura fruit dried only by convective drying.

Keywords: Mass transfer; Osmotic dehydration; Sensory acceptance.

\section{Introdução}

A goiaba é uma fruta das regiões tropicais e subtropicais, e é apreciada pelos consumidores por possuir sabor forte e quantidades consideráveis de vitamina C; porém, a sua curta vida pós-colheita associada ao elevado conteúdo de água torna o fruto susceptível a danos causados no transporte e armazenamento, limitando o seu potencial de comercialização (SAHOO et al., 2015).

A desidratação osmótica é um relevante método de secagem parcial, capaz de diminuir o teor de água por meio da imersão dos frutos em solução concentrada contendo um ou mais solutos, resultando em uma liberação significativa de água do produto para o meio circundante (SOURAKI et al., 2013; CATALDO et al., 2011). Trata-se de um método econômico se comparado à secagem convencional; porém, quando não é capaz de diminuir o teor de água a níveis considerados seguros, em relação às alterações microbiológicas e bioquímicas, o método passa a ser utilizado como pré-tratamento para secagens posteriores (AL-HARAHSHEH et al., 2009; CORRÊA et al., 2010).

Além das vantagens apresentadas quanto à diminuição do conteúdo de água dos alimentos, os métodos combinados de secagem oferecem vantagens nos processos de embalagem e armazenamento, contribuindo também para o desenvolvimento de novos produtos alimentícios.

Estudos referentes à elaboração de passas de goiaba foram realizados (CORRÊA et al., 2010; PESSOA et al., 2011; OLIVEIRA et al., 2014), porém a transferência de massa foi limitada a uma única temperatura de processo. Estudos relacionados à desidratação osmótica de frutas destacam a influência da temperatura na transferência de massa (CAMPOS et al., 2012; FERRARI et al., 2005). Assim, objetivou-se, neste trabalho, estudar o processo de transferência de massa durante a desidratação osmótica de fatias de goiaba, além de avaliar os parâmetros sensoriais da goiaba-passa obtida sob diferentes temperaturas de osmose e concentrações de sacarose.

\section{Material e métodos}

No estudo, utilizou-se goiaba de polpa vermelha da variedade Paluma, obtida no comércio local de frutos de Campina Grande - PB, em estádio de maturação completamente maduro. Os frutos foram selecionados de acordo com a coloração da casca, mostrando-se livres de defeitos fisiológicos, danos físicos e mecânicos, ou de infecções causadas por microrganismos. Depois de adquiridas, as goiabas foram transportadas em sacos plásticos descartáveis até o laboratório de Armazenamento e Processamento de Produtos Agrícolas, pertencente à Universidade Federal de Campina Grande, no qual foram lavadas em água corrente e higienizadas em solução clorada a 50 ppm por 10 minutos. O descascamento foi realizado com auxílio de um descascador de legumes, retirando-se também as sementes dos frutos. O corte da polpa foi realizado manualmente $(3,0 \times 2,0 \mathrm{~cm})$, respeitando-se a espessura natural média do fruto de $0,9 \mathrm{~cm}$.

Para desidratação osmótica, utilizou-se planejamento fatorial $2^{2}$ com três pontos centrais (nível zero) e duas variáveis de entrada: temperatura de processo e concentração do xarope de sacarose. Analisaram-se as seguintes respostas: quantidade de água e incorporação de sólidos durante desidratação osmótica da goiaba. A Tabela 1 mostra o planejamento dos experimentos com os níveis reais e codificados das variáveis. Os mesmos foram escolhidos com base em trabalhos anteriores, que sugerem temperaturas ótimas de desidratação osmótica entre $20^{\circ} \mathrm{C}$ e $50{ }^{\circ} \mathrm{C}$ (BERISTAIN et al., 1990) e soluções desidratantes com alta massa molecular (FONTES et al., 2012).

Os xaropes foram obtidos pela diluição da sacarose em água sob agitação constante, até as concentrações de $40^{\circ}$ Brix, $50^{\circ}$ Brix e $60^{\circ}$ Brix, medidas em refratômetro digital portátil. Os pedaços de goiaba fatiados foram imersos nas soluções na proporção de 1:15 (g/g) fruto/xarope, nas temperaturas de $30^{\circ} \mathrm{C}, 40^{\circ} \mathrm{C}$ e $50^{\circ} \mathrm{C}$. O processo de desidratação osmótica teve duração de 24 horas, estabelecida com base em testes preliminares, tendo em vista a retirada do máximo de água das fatias de goiaba durante a desidratação osmótica.

Tabela 1. Matriz de planejamento fatorial $2^{2}$ com 3 repetições no ponto central, para desidratação osmótica de goiaba em solução de sacarose.

\begin{tabular}{ccc} 
Experimentos & $\begin{array}{r}\text { Temperatura de } \\
\text { processo }\left({ }^{\circ} \mathbf{C}\right)\end{array}$ & $\begin{array}{c}\text { Concentração de } \\
\text { sacarose ( }{ }^{\circ} \text { Brix) }\end{array}$ \\
\hline 1 & $(-1) 30$ & $(-1) 40$ \\
2 & $(+1) 50$ & $(-1) 40$ \\
3 & $(-1) 30$ & $(+1) 60$ \\
4 & $(+1) 50$ & $(+1) 60$ \\
5 & $(0) 40$ & $(0) 50$ \\
6 & $(0) 40$ & $(0) 50$ \\
7 & $(0) 40$ & $(0) 50$ \\
\hline
\end{tabular}


Para o levantamento da cinética de secagem, bem como da incorporação de sólidos, foi feito o acompanhamento de peso das goiabas, em triplicata, nos tempos de 0, 10, 30, 60, 90, 120, 150, 180, 210, 240 e 1.440 minutos.

Para esse acompanhamento, aproximadamente 15 gramas de pedaços de goiabas foram colocados em cestas de arame galvanizado de peso conhecido, pré-identificadas de acordo com o tempo de pesagem $\left.\left(n_{0}, n_{1}, \ldots\right], n_{10}\right)$, conforme Figura 1. A cesta controle $\left(n_{0}\right)$ foi levada para a estufa a $105^{\circ} \mathrm{C}$, para determinação da massa seca inicial da amostra, sendo que as demais amostras foram imersas no xarope. O sistema foi colocado em estufa de circulação de ar, para garantia da temperatura de osmose desejada. Nos tempos de pesagens, para o levantamento da cinética de secagem, as cestas correspondentes ao tempo foram retiradas do xarope e os frutos lavados com água destilada para retirada do filme de açúcar aderido à superfície do fruto. O excesso de água foi removido envolvendo os frutos em papel toalha. As fatias de goiaba foram pesadas e levadas em cestas de arame galvanizado de peso conhecido para estufa a $105^{\circ} \mathrm{C}$, por 4 horas, conforme descrito por Mercali et al. (2011).

Ao final do processo, apenas a amostra $n_{10}$ permanecia na solução e a determinação da sua massa, bem como da massa seca nos tempos anteriores, foram verificadas conforme metodologia descrita por Castro et al. (2014), a partir das Equações 1 e 2:

Massa total:

$\mathrm{m}_{10}^{\mathrm{t}}=\mathrm{m}_{10}^{0} \frac{\mathrm{m}_{\mathrm{x}}^{\mathrm{t}}}{\mathrm{m}_{\mathrm{x}}^{0}}$

em que: $m_{10}^{t}=$ massa da amostra $n_{10}$ no tempo $t ; m_{10}^{0}=$ massa da amostra $n_{10}$ no tempo zero; $m_{x}^{t}=$ massa da amostra $n_{x}$ no tempo $t ; m_{x}^{0}=$ massa de $n_{x}$ no tempo zero.

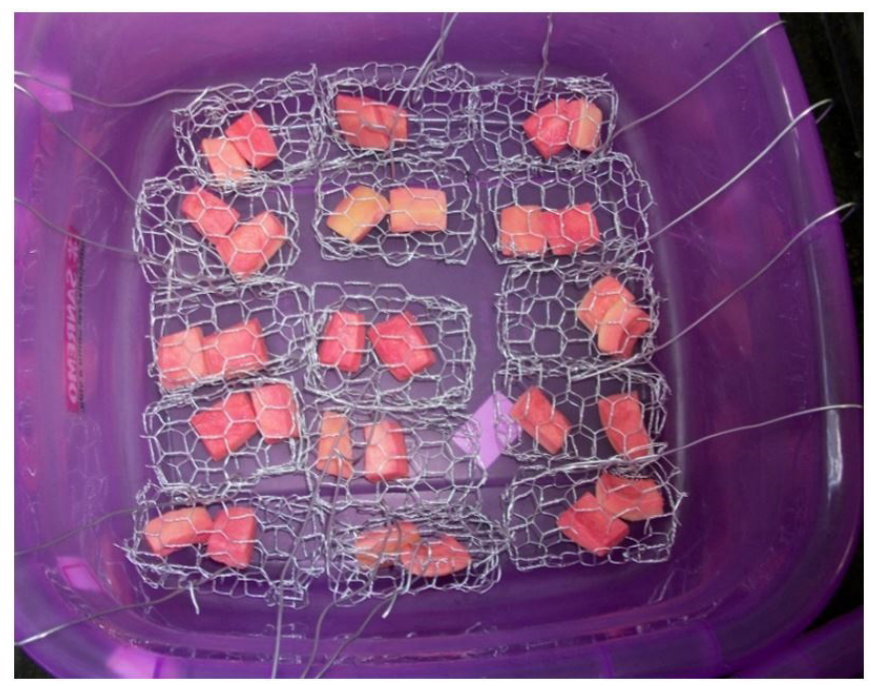

Figura 1. Cestas identificadas para a desidratação osmótica.

$$
\begin{aligned}
& \text { Massa seca: } \\
& \mathrm{ms}_{10}^{\mathrm{t}}=\mathrm{ms}_{\mathrm{x}}^{\mathrm{t}} \frac{\mathrm{m}_{10}^{\mathrm{t}}}{\mathrm{m}_{\mathrm{x}}^{\mathrm{t}}}
\end{aligned}
$$

em que: $\mathrm{ms}_{10}^{\mathrm{t}}=$ massa seca da amostra $\mathrm{n}_{10}$ no tempo $\mathrm{t}$; $\mathrm{ms}_{\mathrm{x}}^{\mathrm{t}}=$ massa seca da amostra $\mathrm{n}_{\mathrm{x}}$ no tempo $\mathrm{t}$.

Para cálculo da massa de água, em cada tempo, utilizou-se a seguinte Equação 3:

$\mathrm{m}_{\mathrm{w}}^{\mathrm{t}}=\mathrm{m}_{10}^{\mathrm{t}}-\mathrm{ms}_{10}^{\mathrm{t}}$

em que: $m_{w}^{t}=$ massa de água da amostra $n_{10}$ no tempo $t$.

A quantidade de água em porcentagem, presente no produto, a cada tempo, foi calculada pela Equação 4:

Quantidade de água $\%=\frac{\mathrm{m}_{\mathrm{w}}^{\mathrm{t}}}{\mathrm{m}_{\mathrm{w}}^{0}} 100$

em que: $\mathrm{m}_{\mathrm{w}}^{0}=$ massa de água no instante zero.

Para cálculo da massa de sólidos, em cada tempo, utilizou-se (Equação 5):

$\mathrm{m}_{\mathrm{s}}^{\mathrm{t}}=\mathrm{ms}_{10}^{\mathrm{t}}-\mathrm{ms}_{10}^{0}$

em que: $\mathrm{m}_{\mathrm{s}}^{\mathrm{t}}=$ massa de sólidos no tempo $\mathrm{t} ; \mathrm{ms}_{10}^{0}=$ massa seca da amostra $n_{10}$ no tempo zero.

A incorporação de sólidos, a cada tempo, foi calculada pela Equação 6:

Incorporação de sólidos $=\frac{\mathrm{m}_{\mathrm{s}}^{\mathrm{t}}}{\mathrm{ms}_{10}^{0}} \times 100$

Após a desidratação osmótica, as goiabas foram acondicionadas em cestas de arame galvanizado e submetidas à secagem convectiva complementar, na temperatura $60{ }^{\circ} \mathrm{C}$, em secador de ar aquecido com circulação forçada de ar, nas quais permaneceram até atingirem teor de água médio de $18 \pm 0,2 \%$ b.u.

As goiabas-passa obtidas por todos os tratamentos da desidratação seguidos de secagem, bem como amostras do fruto sem tratamento osmótico, secas convencionalmente, foram submetidas à avaliação sensorial. O teste sensorial foi aplicado em 51 provadores não treinados, com idades variando entre 18 anos e 63 anos, que avaliaram os atributos aparência, odor, cor, sabor e textura, por meio da escala hedônica, atribuindo notas de 1 (desgostei muito) a 9 (gostei muitíssimo), para cada tratamento. O perfil de atitudes foi avaliado a partir da utilização de uma escala variando de 1 (comeria sempre) a 7 (nunca comeria). Antes da realização da análise sensorial, o projeto foi submetido ao comitê de ética com seres humanos, recebendo aprovação sob o número 610.622.

Os resultados da desidratação osmótica foram analisados nos programas computacionais Statistic 5.0 ${ }^{\circledR}$ e LAB Fit Curve Fitting software (SILVA et al., 2004), para obtenção do gráfico de Pareto e superfícies de resposta, respectivamente. Os dados obtidos nos testes sensoriais foram avaliados pela ANOVA de Kruskal-Wallis, recomendado para dados ordinais, sem normalidade e homogeneidade, 
Desenvolvimento e avaliação sensorial de goiaba-passa desidratada osmoticamente

Castro, D. S. et al.

por meio do programa estatístico Assistat 7.7 Beta (SILVA; AZEVEDO, 2009).

\section{Resultados e discussão}

A partir dos dados de quantidade de água e de incorporação de sólidos obtidos na desidratação osmótica, é possível verificar, na Figura 2, uma perda progressiva de água no início do processo, acompanhada por um rápido ganho de sacarose. As primeiras quatro horas de processo, independentemente do tratamento, foram suficientes para remover, em média, 50\% de toda a quantidade de água retirada após o tempo total de desidratação, com ganhos de sacarose superiores a $60 \%$. Resultados semelhantes foram encontrados por Silva et al. (2012), ao estudarem a desidratação osmótica de acerola.

A grande força motriz encontrada no início do processo de desidratação osmótica é responsável pela intensa perda de água durante as horas iniciais. De acordo com Ferrari et al. (2005), as altas taxas de remoção de água no início do processo são influenciadas pela grande diferença no potencial químico da água do produto e da solução osmótica. Ao longo do tempo, com as trocas entre o produto e o meio osmótico, a força motriz diminui, provocando consequente diminuição na taxa de remoção de água do produto, até que se atinja o equilíbrio osmótico.

A análise de variância (ANOVA) foi aplicada para verificar a significância da regressão e do resíduo no nível de 95\% de confiabilidade, utilizando o teste F (Tabela 2), obtido para a quantidade de água e a incorporação de sólidos, durante a desidratação osmótica. A interpretação dos resultados considera os modelos preditivos no nível de 95\% de confiança, possuindo o F calculado da regressão superior ao F tabelado. De acordo com Rodrigues e lemma (2009), o modelo pode ser considerado estatisticamente significativo quando o valor de F calculado for superior a duas vezes o valor de $F$ tabelado, conforme ocorreu neste processo, em que o valor de $F_{\text {calc }} / F_{\text {tab }}$, para regressão da quantidade de água, foi 2,92, e o valor de $F_{\text {calc }} / F_{\text {tab }}$, para regressão da incorporação de sólidos, foi de 2,93.

Os modelos codificados propostos para representar a quantidade de água e a incorporação de sólidos, na
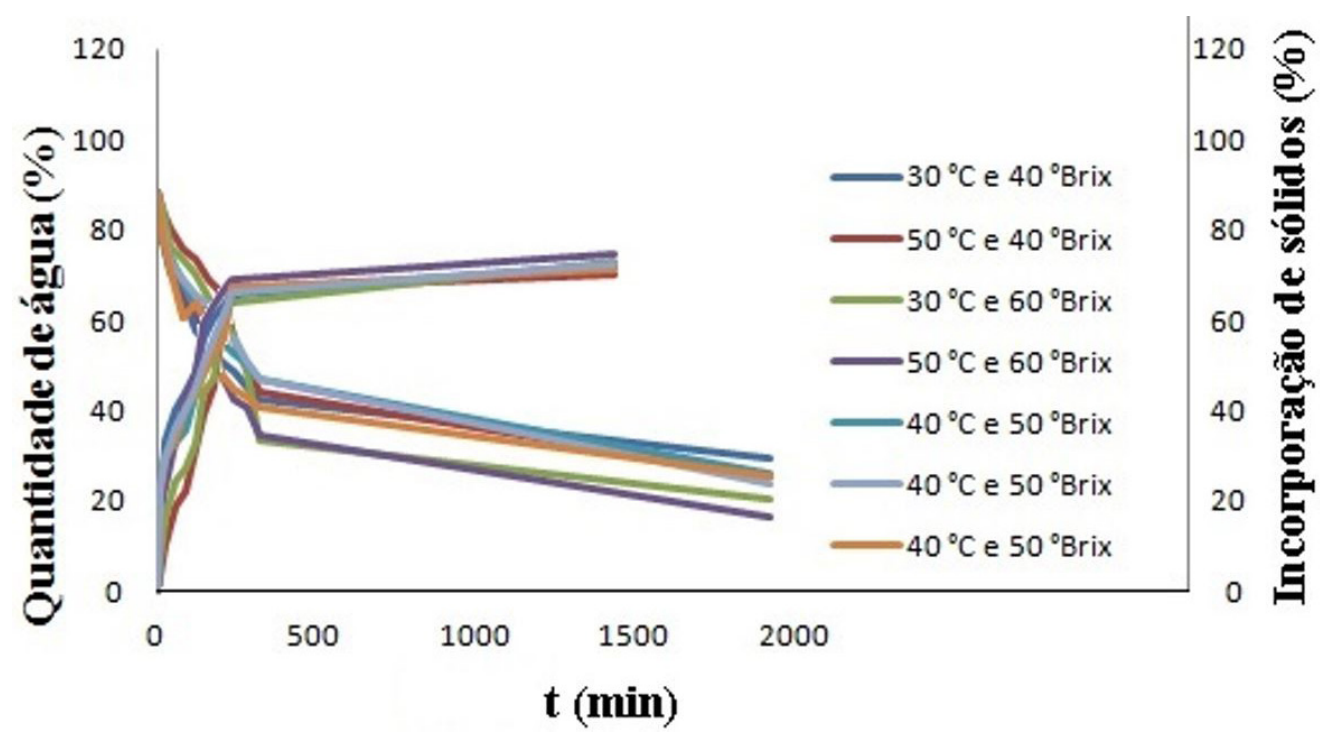

Figura 2. Velocidade de perda de água e ganho de sólidos durante desidratação osmótica.

Tabela 2. Análise de variância (ANOVA) para quantidade de água e de incorporação de sólidos.

\begin{tabular}{|c|c|c|c|c|c|c|}
\hline \multicolumn{7}{|c|}{ Quantidade de água } \\
\hline Fonte de Variação & SQ & GL & QM & $F_{\text {cal }}$ & $F_{\text {tab }}$ & $\mathbf{R}^{2}$ \\
\hline Regressão & 119,46 & 3 & 39,82 & 27,10 & 9,28 & 0,90 \\
\hline Resíduo & 32,27 & 3 & 10,75 & & & \\
\hline Total & 151,73 & 6 & & & & \\
\hline \multicolumn{7}{|c|}{ Incorporação de sólidos } \\
\hline Fonte de Variação & SQ & GL & QM & $\mathbf{F}_{\text {cal }}$ & $F_{\text {tab }}$ & $\mathbf{R}^{2}$ \\
\hline Regressão & 11,51 & 3 & 3,84 & 27,20 & 9,28 & 0,90 \\
\hline Resíduo & 485,75 & 3 & 161,92 & & & \\
\hline Total & 497,26 & 6 & & & & \\
\hline
\end{tabular}


desidratação osmótica de goiaba em solução de açúcar, obtidos a partir de uma regressão, encontram-se descritos nas Equações 7 e 8, cujos coeficientes de determinação $\mathrm{R}^{2} \geq 0,90$ indicam a capacidade do modelo de explicar $90 \%$ das variações dos dados observados. Almeida et al. (2005) também encontraram modelos propostos para o ganho de sólidos superiores a 0,90. Segundo os autores, quanto maior for a fração descrita pela regressão, ou melhor, quanto mais próximo de 1 for o valor de $\mathrm{R}^{2}$, melhor será o ajuste do modelo aos dados observados.

Quantidade de água $(\%)=58,03-0,13 T-0,43 C-0,002 T C \quad(7)$

Incorporação de sólidos $(\%)=85,32-0,50 T-0,26 C-0,009 T C$ (8)

em que: $T$ = temperatura; $C$ = concentração.

As superfícies de respostas obtidas por meio dos modelos propostos para quantidade de água e incorporação de sólidos das goiabas, sob diferentes temperaturas e concentrações de sacarose, a partir do planejamento fatorial $2^{2} \mathrm{com}$ um ponto central, são apresentadas na Figura 3.

Sob as condições de estudo, para se obter uma máxima perda de água das fatias de goiaba em solução de sacarose, é necessária uma temperatura de $50{ }^{\circ} \mathrm{C} \mathrm{e}$ concentração de sacarose de $60^{\circ}$ Brix. O máximo ganho de sólidos é obtido sob condição experimental à temperatura de $50^{\circ} \mathrm{C}$ e concentração da solução osmótica de $60^{\circ}$ Brix.

A análise do gráfico de Pareto da quantidade de água (Figura 4A) mostra a influência da concentração de sacarose sobre a quantidade de água, durante a desidratação osmótica. Esta influência é atribuída à alta concentração da solução, a qual proporciona um grande gradiente de pressão entre o fruto e a solução osmótica, favorecendo uma maior saída de água e tendendo ao equilíbrio com o meio osmótico. Esta relação de influência da concentração osmótica sobre a saída da água do fruto durante a desidratação osmótica é também compartilhada por Germer et al. (2011), que estudaram a desidratação osmótica de pêssegos em função da temperatura e da concentração do xarope de sacarose.

Experimentos realizados a uma maior temperatura mostraram redução na quantidade de água retida, apesar de esta variável apresentar um menor efeito de influência, quando comparada à concentração da solução nessa resposta (Figura 4A). Rodríguez et al. (2013) não observaram influência significativa da temperatura sobre
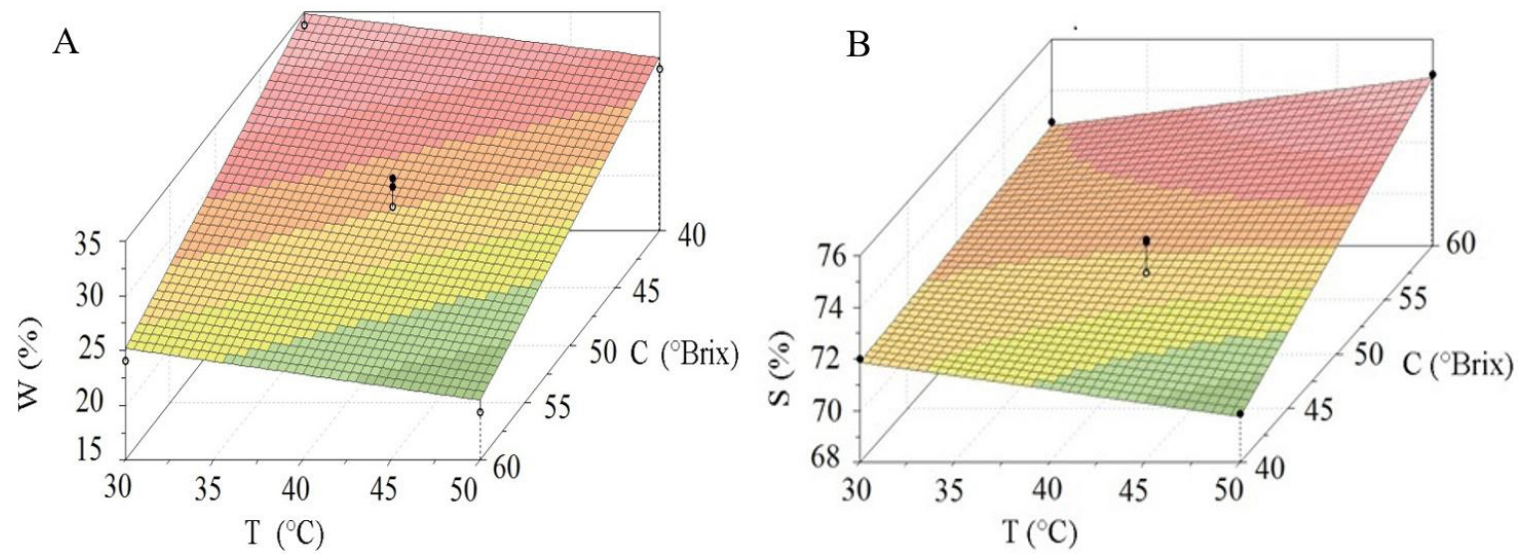

Figura 3. Superfície de resposta para a quantidade de água (A) e incorporação de sólidos (B).
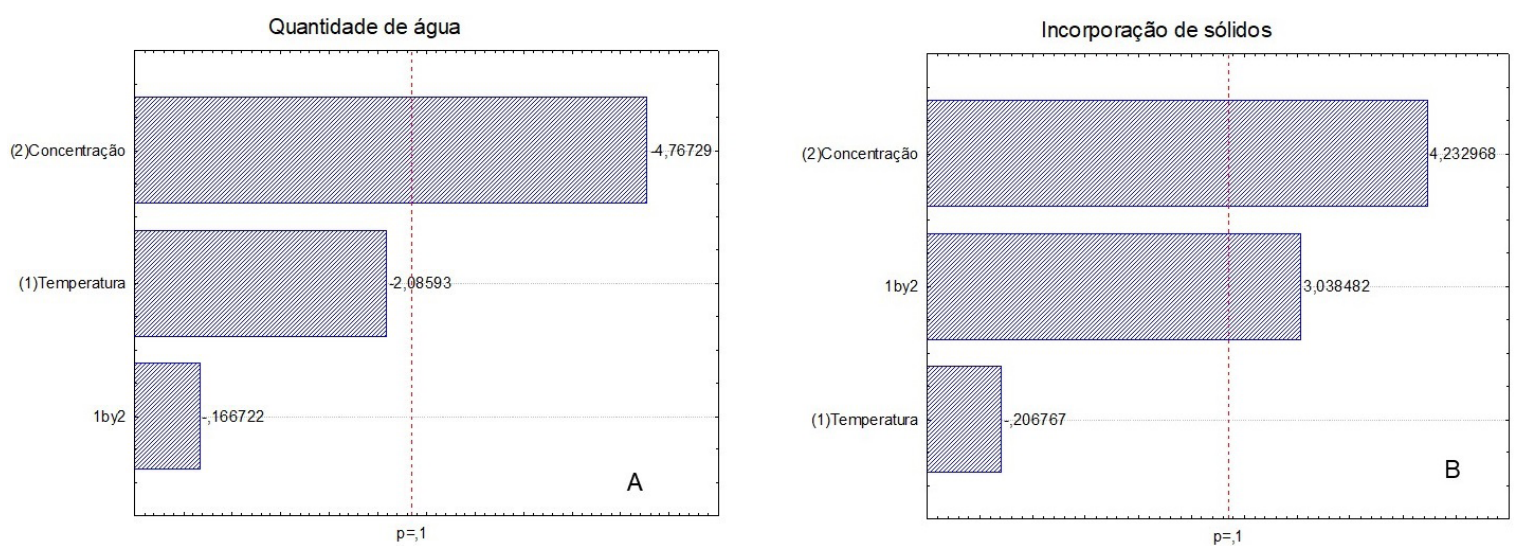

Figura 4. Gráfico de Pareto das variáveis de influência da quantidade de água (A) e incorporação de sólidos (B). 
a perda de água em seus estudos sobre a desidratação osmótica de nectarinas.

Quanto ao ganho de sólidos, estudos revelam que a taxa de transferência na desidratação osmótica depende em grande parte do tamanho molecular do soluto, bem como de parâmetros do processo, tais como a concentração da solução e a temperatura (LAZARIDES et al., 1995). A Figura 4B mostra a influência das variáveis, temperatura de processo e concentração de sacarose, bem como a interação entre as mesmas sobre o ganho de sacarose durante a desidratação osmótica.

O aumento da concentração da solução de $40^{\circ}$ Brix para $60^{\circ}$ Brix, à temperatura de $30^{\circ} \mathrm{C}$, proporcionou um ganho de sólido de 1,1 g $100 \mathrm{~g}^{-1}$ amostra. Quando o mesmo aumento de concentração ocorre à temperatura de $50{ }^{\circ} \mathrm{C}$, o ganho de sólidos da goiaba aumentou em

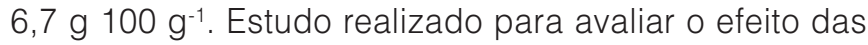
condições de desidratação de laranja (MENDES et al., 2013) também mostrou que a concentração da solução osmótica tem efeito positivo no ganho de sólidos. Os autores reportaram um aumento de 1,6 g $100 \mathrm{~g}^{-1}$ com o aumento da concentração da solução de $30^{\circ}$ Brix para $60^{\circ}$ Brix, sob uma temperatura de $20^{\circ} \mathrm{C}$.

De acordo com a Figura 4B, tanto a temperatura quanto a interação entre as duas variáveis (concentração x temperatura) exerceram uma menor influência na incorporação de sólidos. Rahman e Lamb (1990) observaram que, em alta temperatura, o soluto não se difunde tão facilmente através da membrana celular. Da mesma forma, Beristain et al. (1990) afirmaram que o ganho de sólidos durante a desidratação osmótica é menos influenciado pela temperatura.

O resultado das médias dos atributos sensoriais avaliados pelo teste de Kruskal-Wallis é apresentado na Tabela 3, na qual se observa diferença significativa, a 95\% de confiança, entre as médias das características avaliadas, para cada tratamento.

As goiabas-passa obtidas pelos tratamentos $40{ }^{\circ} \mathrm{Brix} / 30{ }^{\circ} \mathrm{C}, 40^{\circ} \mathrm{Brix} / 50{ }^{\circ} \mathrm{C}$ e $60{ }^{\circ} \mathrm{Brix} / 30^{\circ} \mathrm{C}$ não apresentaram diferença significativa entre as médias atribuídas pelos provadores para o atributo aparência; porém, diferiram dos demais tratamentos.
As maiores médias atribuídas para a aparência foram para as goiabas-passa obtidas sob os tratamentos a $40^{\circ} \mathrm{Brix} / 50^{\circ} \mathrm{C}$ e $40^{\circ} \mathrm{Brix} / 30^{\circ} \mathrm{C}$, classificando-as como "gostei moderadamente", de acordo com a escala hedônica de 9 pontos utilizada no teste de aceitabilidade. A menor média foi obtida para a goiaba sem tratamento osmótico.

A média de cor dos tratamentos $50{ }^{\circ}$ Brix $/ 40{ }^{\circ} \mathrm{C}$ e $60^{\circ} \mathrm{Brix} / 50^{\circ} \mathrm{C}$ e sem tratamento osmótico foram estatisticamente distintas das médias de cor atribuídas para os demais tratamentos. As médias atribuídas pelos provadores correspondem a "gostei extremamente" na escala hedônica de 9 pontos, para a cor do tratamento $40^{\circ}$ Brix $/ 30^{\circ} \mathrm{C}$, assim como os tratamentos de $40^{\circ} \mathrm{Brix} / 50^{\circ} \mathrm{C}$ e $60^{\circ} \mathrm{Brix} / 30^{\circ} \mathrm{C}$.

Não houve diferença entre as médias dos tratamentos para o atributo odor. Por tratar-se de um fruto com odor forte e característico, os tratamentos pouco influenciaram a aceitação do odor das passas, porém são perceptíveis as maiores médias para os tratamentos desidratados na concentração de $40{ }^{\circ}$ Brix e $60^{\circ}$ Brix.

$\mathrm{O}$ atributo textura apresentou semelhança estatística apenas entre os tratamentos $40^{\circ} \mathrm{Brix} / 30^{\circ} \mathrm{C}$ e $60^{\circ} \mathrm{Brix} / 30^{\circ} \mathrm{C}$. A maior média foi atribuída às passas obtidas no tratamento a $40{ }^{\circ}$ Brix $/ 50{ }^{\circ} \mathrm{C}$, cuja média corresponde a "gostei moderadamente", conforme a escala utilizada. O tratamento que obteve maior rejeição foi a passa produzida sob as condições de $50{ }^{\circ}$ Brix $/ 40{ }^{\circ} \mathrm{C}$.

As médias atribuídas ao sabor das passas não apresentaram diferença estatística para os tratamentos de $40{ }^{\circ} \mathrm{Brix} / 30^{\circ} \mathrm{C}, 60^{\circ} \mathrm{Brix} / 30^{\circ} \mathrm{C}$ e $60^{\circ} \mathrm{Brix} / 50{ }^{\circ} \mathrm{C}$, cujos valores correspondem a "gostei ligeiramente". Os tratamentos $40^{\circ} \mathrm{Brix} / 50^{\circ} \mathrm{C}$ e $50{ }^{\circ} \mathrm{Brix} / 40{ }^{\circ} \mathrm{C}$ e sem tratamento osmótico apresentaram-se estatisticamente distintos entre si, revelando a preferência de sabor para as passas obtidas nas condições de $40^{\circ}$ Brix $/ 50^{\circ} \mathrm{C}$, com a maior nota.

O perfil de atitude atribuído pelos provadores para as amostras, representado graficamente na Figura 5, utiliza a escala de 1 - comeria sempre a 7 - nunca comeria. As médias com maior proximidade do centro, no gráfico de teia, indicam as amostras de maior preferência entre os provadores.

Tabela 3. Médias dos atributos sensoriais avaliados para cada tratamento osmótico seguido de secagem a $60^{\circ} \mathrm{C}$.

\begin{tabular}{|c|c|c|c|c|c|}
\hline \multirow{2}{*}{ Tratamentos } & \multicolumn{5}{|c|}{ Características avaliadas } \\
\hline & Aparência & Cor & Odor & Textura & Sabor \\
\hline $40^{\circ}$ Brix $/ 30^{\circ} \mathrm{C}$ & $7,19 \mathrm{c}$ & $7,37 \mathrm{c}$ & $7,25 \mathrm{a}$ & $6,29 \mathrm{bc}$ & $6,49 \mathrm{bc}$ \\
\hline $40^{\circ}$ Brix $/ 50^{\circ} \mathrm{C}$ & $7,35 \mathrm{c}$ & $7,27 \mathrm{c}$ & $6,82 \mathrm{a}$ & $6,98 \mathrm{c}$ & $6,72 \mathrm{c}$ \\
\hline $60^{\circ}$ Brix $/ 30^{\circ} \mathrm{C}$ & $7,14 \mathrm{c}$ & $7,15 \mathrm{c}$ & $7,23 \mathrm{a}$ & $6,00 \mathrm{bc}$ & $6,41 \mathrm{bc}$ \\
\hline $60^{\circ}$ Brix $/ 50^{\circ} \mathrm{C}$ & $6,84 \mathrm{bc}$ & $6,90 \mathrm{bc}$ & $6,90 \mathrm{a}$ & $5,33 a b$ & $6,29 \mathrm{bc}$ \\
\hline $50^{\circ}$ Brix $/ 40^{\circ} \mathrm{C}$ & $5,80 a b$ & $5,90 a b$ & $6,70 \mathrm{a}$ & $4,70 \mathrm{a}$ & $5,57 \mathrm{~b}$ \\
\hline Sem tratamento osmótico & $5,19 a$ & $5,70 \mathrm{a}$ & $6,47 \mathrm{a}$ & $5,51 a b$ & $4,02 \mathrm{a}$ \\
\hline
\end{tabular}

As médias seguidas pela mesma letra não diferem estatisticamente entre si. 


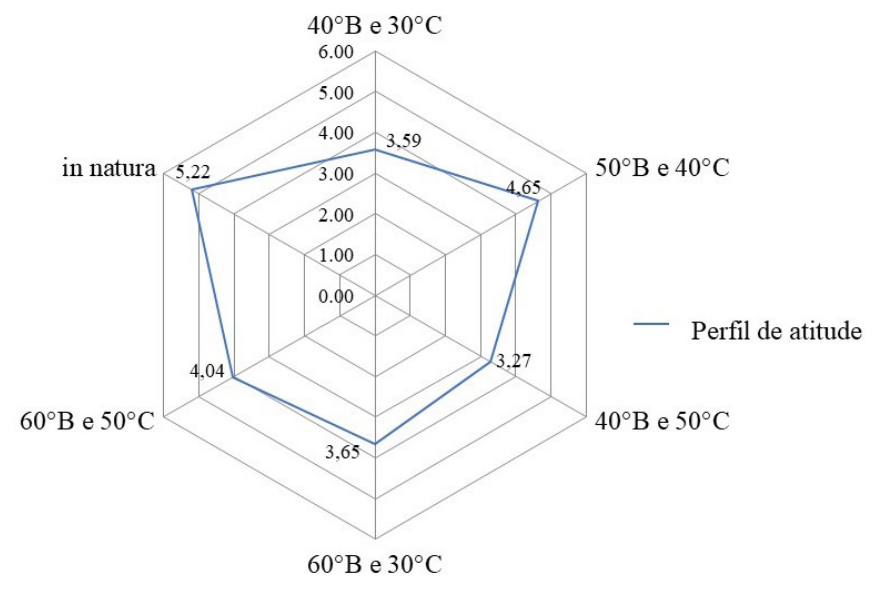

Figura 5. Perfil de atitudes atribuído aos diferentes tratamentos da goiaba-passa.

A preferência dos provadores para os tratamentos obtidos na concentração de $40^{\circ}$ Brix prevaleceu em todos os atributos avaliados no teste sensorial. O tratamento osmótico manteve-se bem aceito e preferido, em relação ao fruto sem tratamento osmótico, seco convencionalmente.

Pessoa et al. (2011), ao analisarem a aceitação de goiabas submetidas a desidratação osmótica e secagem, também revelaram boa aceitação para os tratamentos obtidos sob a concentração de $40^{\circ}$ Brix.

\section{Conclusão}

A transferência de massa durante a desidratação osmótica das fatias de goiaba foi influenciada pela concentração de sacarose, enquanto que a temperatura exerceu menor influência no processo.

O modelo matemático obtido pelo planejamento experimental é indicado para explicar $90 \%$ da variação dos dados observados.

A goiaba-passa obtida pela desidratação em $40{ }^{\circ}$ Brix sob as temperaturas de $30^{\circ} \mathrm{C}$ e $50^{\circ} \mathrm{C}$ foram as preferidas entre os provadores para os atributos aparência, cor, textura e sabor.

\section{Referências}

AL-HARAHSHEH, M.; AL-MUHTASEB, A. H.; MAGEE, T. R. A. Microwave drying kinetics of tomato pomace: effect of osmotic dehydration. Chemical Engineering and Processing, v. 48, n. 1, p. 524-531, 2009. http://dx.doi.org/10.1016/j.cep.2008.06.010.

ALMEIDA, F. A. C.; RIBEIRO, C. F. A.; TOBINAGA, S.; GOMES, J. P. Otimização do processo de secagem osmótica na obtenção de produtos secos de manga Tommy Atkins. Revista Brasileira de Engenharia Agrícola e Ambiental, v. 9, n. 4, p. 576-584, 2005. http://dx.doi.org/10.1590/S1415-43662005000400022.

BERISTAIN, C. I.; AZUARA, E.; CORTES, R.; GARCIA, H. S. Mass transfer during osmotic dehydration of pineapple rings.
International Journal of Food Science \& Technology, v. 25, n. 5, p. 576-582, 1990. http://dx.doi.org/10.1111/j.1365-2621.1990. tb01117.x.

CAMPOS, C. D. M.; SATO, A. C. K.; TONON, R. V.; HUBINGER, M. D.; CUNHA, R. L. Efeito das variáveis de processo na desidratação osmótica de fatias de carambola. Ciência e Tecnologia de Alimentos, v. 32, n. 2, p. 357-365, 2012.

CASTRO, D. S.; NUNES, J. S.; SILVA JÚNIOR, A. F.; AIRES, J. E. F.; SILVA, W. P.; GOMES, J. P. Influência da temperatura no processo de desidratação osmótica de pedaços de goiaba. Revista GEINTEC, v. 4, n. 5, p. 1413-1423, 2014.

CATALDO, A.; CANNAZZA, G.; BENEDETTO, E.; SEVERINI, C.; DEROSSI, A. An alternative method for the industrial monitoring of osmotic solution during dehydration of fruit and vegetables: a test-case for tomatoes. Journal of Food Engineering, v. 105, n. 1 , p. 186-192, 2011. http://dx.doi.org/10.1016/j.jfoodeng.2011.02.026.

CORRÊA, J. L. G.; PEREIRA, L. M.; VIEIRA, G. S.; HUBINGER, M. $D$. Mass transfer kinetics of pulsed vacuum osmotic dehydration of guavas. Journal of Food Engineering, v. 96, n. 4, p. 498-504, 2010. http://dx.doi.org/10.1016/j.jfoodeng.2009.08.032.

FERRARI, C. C.; RODRIGUES, L. K.; TONON, R. V.; HUBINGER, M. D. Cinética de transferência de massa de melão desidratado osmoticamente em soluções de sacarose e maltose. Revista Ciência e Tecnologia de Alimentos, v. 25, n. 3, p. 564-570, 2005. http://dx.doi.org/10.1590/S0101-20612005000300028.

FONTES, B. C. L.; SIVI, T. C.; RAMOS, K. K.; QUEIROZ, F. P. C. Efeito das condições operacionais no processo de desidratação osmótica de batata-doce. Revista Brasileira de Produtos Agroindustriais, v. 14, n. 1, p. 1-13, 2012. http://dx.doi. org/10.15871/1517-8595/rbpa.v14n1p1-13.

GERMER, S. P.; QUEIROZ, M. R.; AGUIRRE, J. M.; BERBARI, S. A. G.; ANJOS, V. D. Desidratação osmótica de pêssegos em função da temperatura e concentração do xarope de sacarose. Revista Brasileira de Engenharia Agrícola e Ambiental, v. 15, n. 2, p. 161-169, 2011. http://dx.doi.org/10.1590/S141543662011000200008.

LAZARIDES, H. N.; KATSANIDIS, E.; NICKOLAIDIS, A. Mass transfer kinetics during osmotic preconcentration aiming at minimal solid uptake. Journal of Food Engineering, v. 25, n. 2, p. 151-166, 1995. http://dx.doi.org/10.1016/0260-8774(94)00006-U.

MENDES, G. R. L.; FREITAS, C. H.; SCAGLIONI, P. T.; SCHMIDT, C. G.; FURLONG, E. B. Condições para desidratação osmótica de laranjas e as propriedades funcionais do produto. Revista Brasileira de Engenharia Agrícola e Ambiental, v. 17, n. 11, p. 1210-1216, 2013. http://dx.doi.org/10.1590/S141543662013001100012.

MERCALI, G. D.; MARCZAK, L. D. F.; TESSARO, I. C.; NOREÑA, C. P. Z. Evaluation of water, sucrose and $\mathrm{NaCl}$ effective diffusivities during osmotic dehydration of banana (Musa sapientum, shum.). 
Desenvolvimento e avaliação sensorial de goiaba-passa desidratada osmoticamente

Castro, D. S. et al.

Lebensmittel-Wissenschaft + Technologie, v. 44, n. 1, p. 82-91, 2011. http://dx.doi.org/10.1016/j.Iwt.2010.06.011.

OLIVEIRA, R. F.; SANTOS, L. M. M.; CLEMENTE, E. Physicochemical characteristics of guava "Paluma" submitted to osmotic dehydration. Acta Scientiarum. Technology, v. 36, n. 4, p. 733-737, 2014. http://dx.doi.org/10.4025/actascitechnol.v36i4.19798.

PESSOA, T.; AMARAL, D. S.; DUARTE, M. E. M.; MATA, M. E. R. M. C.; GURJÃO, F. F. Avaliação sensorial de goiabas passas obtida por técnicas combinadas de desidratação osmótica e secagem. Revista Holos, v. 4, n. 1, p. 137-147, 2011. http:// dx.doi.org/10.15628/holos.2011.638.

RAHMAN, M. S.; LAMB, J. Osmotic dehydration of pineapple. Journal of Food Science and Technology, v. 27, n. 3, p. 150-152, 1990.

RODRIGUES, M. I.; IEMMA, A. F. Planejamento de experimentos e otimização de processos. 2. ed. Campinas: Casa do Pão, 2009. 325 p.

RODRÍGueZ, M. M.; ARBALLO, J. R.; CAMPAÑONE, L. A.; COCCONI, M. B.; PAGANO, A. M.; MASCHERONI, R. H. Osmotic dehydration of nectarines: influence of the operating conditions and determination of the effective diffusion Coefficients. Food and Bioprocess Technology, v. 6, n. 10, p. 2708-2720, 2013. http://dx.doi.org/10.1007/s11947-012-0957-8.
SAHOO, N. R.; PANDA, M. K.; BAL, L. M.; PAL, U. S.; SAHOO, D. Comparative study of MAP and shrink wrap packaging techniques for shelf life extension of fresh guava. Scientia Horticulturae, v. 182, n. 23, p. 1-7, 2015. http://dx.doi.org/10.1016/j. scienta.2014.10.029.

SILVA, F. A. S.; AZEVEDO, C. A. V. Principal components analysis in the software assistat-Statistical Attendance. In: WORLD CONGRESS ON COMPUTERS IN AGRICULTURE, 7., 2009, Reno, NV. Reno: American Society of Agricultural and Biological Engineers, 2009.

SILVA, M. A. C.; SILVA, Z. E.; MARIANI, V. C.; DARCHE, S. Mass transfer during the osmotic dehydration of West indian cherry. Lebensmittel-Wissenschaft + Technologie, v. 45, n. 2, p. 246-252, 2012. http://dx.doi.org/10.1016/j.Iwt.2011.07.032. SILVA, W. P.; SILVA, C. M. D. P. S.; CAVALCANTI, C. G. B.; SILVA, D. P. S.; SOARES, I. B.; OLIVEIRA, J. A. S.; SILVA, C. D. P. S. "LAB Fit ajuste de curvas": um software em português para tratamento de dados experimentais. São Paulo. Revista Brasileira de Ensino de Física, v. 26, n. 4, p. 419-427, 2004. http://dx.doi.org/10.1590/S1806-11172004000400018.

SOURAKI, B. A.; GHAVAMI, M.; TONDRO, H. Mass transfer during osmotic dehydration of green bean in salt solution: A polynomial approximation approach. Food and Bioproducts Processing, v. 91, n. 3, p. 257-263, 2013. http://dx.doi.org/10.1016/j. fbp.2012.11.002. 